\title{
An Infra-marginal Analysis of the Ricardian Model
}

Wen Li Cheng, Jeffrey D. Sachs, and Xiaokai Yang

CID Working Paper No. 13

April 1999

(c) Copyright 1999 Wen Li Cheng, Jeffrey D. Sachs, Xiaokai Yang, and the President and Fellows of Harvard College
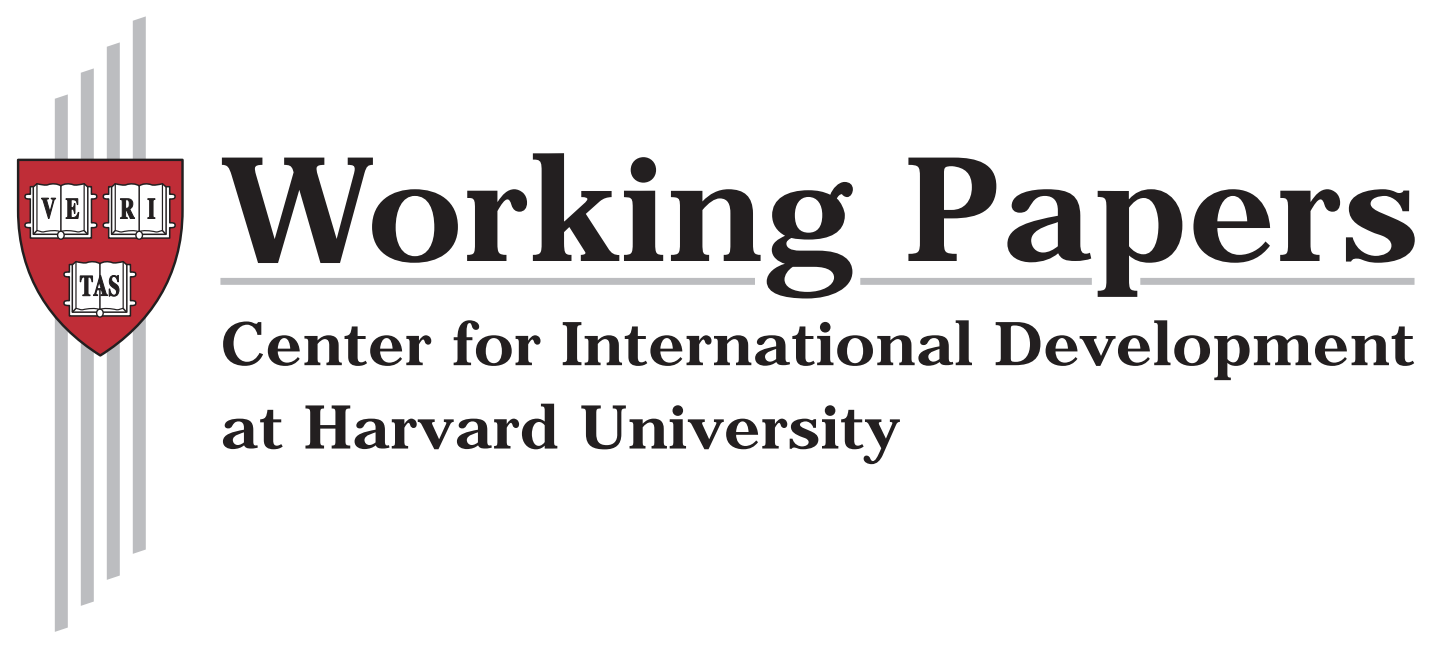


\title{
An Infra-marginal Analysis of the Ricardian Model
}

\author{
Wen Li Cheng, Jeff Sachs, and Xiaokai Yang*
}

\begin{abstract}
This paper applies the infra-marginal analysis, which is a combination of marginal and total cost-benefit analysis, to the Ricardian model. It demonstrates that the rule of marginal cost pricing does not always hold. It shows that in a $2 \times 2$ Ricardian model, there is a unique general equilibrium and that the comparative statics of the equilibrium involve discontinuous jumps -- as transaction efficiency improves, the general equilibrium structure jumps from autarky to partial division of labor and then to complete division of labor. The paper also discusses the effects of tariff in a model where trade regimes are endogenously chosen. It finds that (1) if partial division of labor occurs in equilibrium, the country that produces both goods chooses unilateral protection tariff, and the country producing a single good chooses unilateral laissez faire policy; (2) if complete division of labor occurs in equilibrium, the governments in both countries would prefer a tariff negotiation to a tariff war. Finally, the paper shows that in a model with three countries the country which does not have a comparative advantage relative to the other two countries and/or which has low transaction efficiency may be excluded from trade.
\end{abstract}

Keywords: Ricardo model, trade policy, division of labor

JEL codes: F10, F13, D50

Wen Li Cheng is a senior economist with Law \& Economics Consulting Group. She has written on subjects ranging from the origin of money, economic growth, international trade to government expenditure in New Zealand, network industry regulation in New Zealand and the New Zealand Dairy industry. Her current research interests include equilibrium network of division of labor and industrial organization.

Jeffrey D. Sachs is the Director of the Center for International Development and the Harvard Institute for International Development, and the Galen L. Stone Professor of International Trade in the Department of Economics. His current research interests include emerging markets, global competitiveness, economic growth and development, transition to a market economy, international financial markets, international macroeconomic policy coordination and macroeconomic policies in developing and developed countries.

Xiaokai Yang is a Research Fellow at the Center for International Development. His research interests include equilibrium network of division of labor, endogenous comparative advantages, inframarginal analysis of patterns of trade and economic development.

*We are grateful to Elhanan Helpman, Lin Zhou, Monchi Lio, Meng-Chung Liu, the referee for Review of International Economics, and the participants of the seminar at Monash University for helpful comments. The financial support from Australian Research Council Large Grant A79602713 is gratefully acknowledged. We are solely responsible for the remaining errors. 


\title{
An Infra-marginal Analysis of the Ricardian Model
}

\author{
Wen Li Cheng, Jeff Sachs, and Xiaokai Yang
}

\section{Introduction}

Ricardo's theory of comparative advantage (see Ricardo, 1817) is regarded as the foundation of the modern trade theory. However, the Ricardian model has not attracted the attention it deserves. This lack of attention is attributable to the fact that the conventional marginal analysis is not applicable to the Ricardian model and trade theorists have shown a remarkable insistence in the marginal technique ${ }^{1}$.

There have been only a few non-marginal analyses of the Ricardian model in the literature. Houthakker (1976) proposed a computational method to calculate the equilibrium pattern of division of labor in a two-country, many-commodity Ricardian model. Rosen (1978) applied linear programming to study the optimum work assignment in the presence of comparative advantage. He suggested that the economies of division of labor is not a technical concept, but a concept that describes social interdependence (or "superadditivity" in Rosen's terminology): the more interactions among individuals, the greater scope for productivity improvement ${ }^{2}$.

Rosen's work represents a significant step away from the marginal analysis. However, designed to address a firm's work assignment problem, his model does not immediately relate to

\footnotetext{
${ }^{1}$ Dixit and Norman (1980) noted, "The Ricardo model is unsuitable for comparative statics. The phenomenon of multiple output choices with non-differentiable revenue functions makes it difficult to apply most standard techniques of analysis. For analyses which need single valued supply choices, therefore, attention has shifted to a post-Ricardian model" where "the factor(s) has diminishing returns in each use. Price change then cause a smooth shift of the factor from one use to another."(p.38)

${ }^{2}$ Rosen (1978) demonstrated that the ex post elasticities of substitution is not determined by the production technology, but by the division of labor corresponding to the optimum work assignment.
} 
international trade. In this paper, we use a non-marginal approach similar to Rosen's (1978) to study the trade patterns and related issues in the Ricardian model. We intend to show that with a non-marginal approach, the original Ricardian model can generate numerous insights in a simple and intuitive way.

We refer to the non-marginal approach in this paper as the infra-marginal analysis. The infra-marginal analysis is, loosely speaking, a combination of marginal and total cost-benefit analysis. We shall discuss the features of the infra-marginal analysis later in this paper. In particular, we shall demonstrate that the infra-marginal analysis is consistent with a decentralized decision-making process, and that the marginal cost pricing rule does not always hold. We shall also show that when the infra-marginal analysis is applied, two types of comparative static analyses can be conducted. The first type is the conventional comparative statics which involve continuous changes in endogenous variables in response to a small change in a parameter. The second type involves discontinuous jumps of endogenous variables among different patterns of trade when changes in a parameter exceed certain threshold values. ${ }^{3}$

Using the infra-marginal analysis, we shall examine several issues associated with international division of labor. Firstly, we incorporate transaction costs into the simple $2 \mathrm{x} 2$ Ricardian model and analyze the relationship between transaction costs and the division of labor. According to Adam Smith (1776), the division of labor is limited by the extent of the market (Chapter 3), and the extent of the market is determined by transportation costs (p.31-32). We shall formalize Smith's conjecture in our model.

Secondly, we examine the effect of tariff in a $2 \times 2$ Ricardian model and show that (1) if partial division of labor occurs in equilibrium, the country that produces both goods chooses 
unilateral protection tariff, and the country producing a single good chooses unilateral laissez faire policy; and (2) if complete division of labor occurs in equilibrium, the governments in both countries would prefer a tariff negotiation, which generates bilateral laissez faire regime, to a tariff war. This result can be used to explain why unilateral protection tariff and unilateral laissez. faire may coexist; and why tariff negotiations may sometimes be essential for realizing a laissez faire regime even if trade liberalization is mutually beneficial. This result also seems to be consistent with our observation of a policy shift from unilateral protection tariff to tariff negotiation and trade liberalization (which is sometimes referred to as a shift from import substitution strategy to export substitution strategy).

Finally, we show that in a $3 \times 2$ model the country that has no comparative advantage to the other two countries and/or which has the lowest transaction efficiency may be excluded from trade. We shall apply this result to address the issue of international competitiveness and to examine formally whether international competitiveness makes a difference to the welfare of a nation. $^{4}$

The rest of this paper is organized as follows. Section 2 presents the general equilibrium 2x2 Ricardian model with transaction costs and discusses the implications of the infra-marginal analysis. Section 3 examines the effects of tariff. Section 4 considers a $3 \times 2$ model. The concluding section summarizes the findings of the paper and suggests possible extensions.

\footnotetext{
${ }^{3}$ A recent survey on the growing literature of inframarginal analysis and endogenous specialization can be found from Yang and S. Ng (1998).

${ }^{4}$ Dornbusch, Fischer, and Samuelson (1977) have developed the Ricardo model to the case with a continuum of goods. Also, Gomery (1994) and Houthakker (1976) have introduced many goods into the Ricardo model. But as the numbers of goods and countries increase, the number of configurations and structures increases more than proportionally, so does the degree of complexity of inframarginal analysis. Hence, we leave a model with many goods to the future research.
} 


\section{A Simple $2 \times 2$ Ricardian Model and the Infra-marginal Analysis}

\subsection{The model setting}

Under the usual assumptions of the Ricardian model, consider a world consisting of country 1 and country 2 , each with $M_{i}(i=1,2)$ consumer-producers. The individuals within a country are assumed to be identical. The utility function for individuals in country $i$ is

$U_{i}=\left(x_{i}+k x_{i}^{d}\right)^{\beta}\left(y_{i}+k y_{i}^{d}\right)^{1-\beta}$

where $x_{i}, y_{i}$ are quantities of goods $\mathrm{X}$ and Y produced for self-consumption, $x_{i}{ }^{d}, y_{i}^{d}$ are quantities of the goods $\mathrm{X}$ and $\mathrm{Y}$ bought from the market, and $k$ is the transaction efficiency coefficient. The transaction cost is assumed to take the iceberg form: for each unit of good bought, a fraction (1-k) is lost in transit, the remaining fraction $k$ is received by the buyer.

The production functions for a consumer-producer in country $i$ are

$$
x_{i}+x_{i}^{s}=a_{i x} l_{i x}
$$$$
y_{i}+y_{i}^{s}=a_{i y} l_{i y}
$$

where $x_{i}^{s}, y_{i}^{s}$ are quantities of goods $\mathrm{X}$ and $\mathrm{Y}$ sold; $l_{i x}$ and $l_{i y}$ are the proportions of labor devoted to the production of $\operatorname{good} \mathrm{X}$ and $\operatorname{good} \mathrm{Y}$, and $l_{i x}+l_{i y}=1$.

The decision problem for an individual in country $i$ involves deciding on what and how much to produce for self-consumption, to sell and to buy from the market. In other words, the individual chooses six variables $x_{i}, x_{i}{ }^{s}, x_{i}{ }^{d}, y_{i}, y_{i}{ }^{s}, y_{i}{ }^{d} \geq 0$. We refer to each individual's choice of what to produce, buy and sell as a configuration.

Without loss of generality, let country 1 have a comparative advantage in producing good X, i.e., $a_{1 x} / a_{1 y}>a_{2 x} / a_{2 y}$. There are three types of configurations from which the individuals can choose: 
(1) self sufficiency. Configuration $\mathrm{XY}$, where an individual produces both goods for selfconsumption. This configuration is defined by $x_{i}, y_{i}>0, x_{i}^{s}=x_{i}{ }^{d}=y_{i}{ }^{s}=y_{i}{ }^{d}=0, i=1,2$.

(2) partial specialization in the comparative advantage good. Configuration $\mathrm{XY} / \mathrm{Y}$, where an individual produces both $\mathrm{X}$ and $\mathrm{Y}$, sell $\mathrm{X}$ in exchange for $\mathrm{Y}$. This configuration is relevant for individuals in country 1 (as country 1 is assumed to have a comparative advantage in producing good X), and is defined by $x_{1}, y_{1}, x_{1}{ }^{s}, y_{1}{ }^{d}>0, x_{1}{ }^{d}=y_{1}{ }^{s}=0$. Configuration XY/X, where an individual produces both $\mathrm{X}$ and $\mathrm{Y}$, sells $\mathrm{Y}$ in exchange for $\mathrm{X}$. This configuration is relevant to individuals in country 2 , and is defined by $x_{2}, y_{2}, x_{2}{ }^{d}, y_{2}{ }^{s}>0, x_{2}{ }^{s}=y_{2}{ }^{d}=0$.

(3) complete specialization in the comparative advantage good. Configuration $\mathrm{X} / \mathrm{Y}$ where an individual produces only $\mathrm{X}$, sells $\mathrm{X}$ in exchange for $\mathrm{Y}$, and configuration $\mathrm{Y} / \mathrm{X}$ where an individual produces only $\mathrm{Y}$, sells $\mathrm{Y}$ in exchange for $\mathrm{X}$. Configuration $\mathrm{X} / \mathrm{Y}$ is relevant for individuals in country 1 and is defined by $x_{1}, x_{1}{ }^{s}, y_{1}{ }^{d}>0, x_{1}{ }^{d}=y_{1}=y_{1}{ }^{s}=0$; configuration Y/X is relevant for individuals in country 2 and is defined by $y_{2},{y_{2}}^{s}, x_{2}{ }^{d}>0, y_{2}{ }^{d}=x_{2}=x_{2}{ }^{s}=0$.

The combination of all individual's configurations constitutes a market structure, or structure for short. Given the configurations listed above, there are four feasible structures, as illustrated in Figure 1.

Structure A is an autarky structure where individuals in both countries choose selfsufficiency (configuration $\mathrm{XY}$ ). Structures $\mathrm{Ba}$ and $\mathrm{Bb}$ are partial division of labor structures where individuals in one country produce both goods $\mathrm{X}$ and $\mathrm{Y}$ and sell their comparative advantage good in exchange for their comparative disadvantage good. Structure C is the complete division of labor structure where individuals in country 1 produce $\mathrm{X}$ and buy $\mathrm{Y}$ 
(configuration $\mathrm{X} / \mathrm{Y}$ ), and individuals in country 2 produce $\mathrm{Y}$ and buy $\mathrm{X}$ (configuration $\mathrm{Y} / \mathrm{X}$ ). It can be shown that structures in which some countries export comparative disadvantage goods cannot occur in general equilibrium.

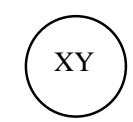

Country 1

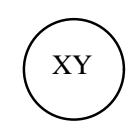

Country 2

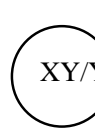

Country 1

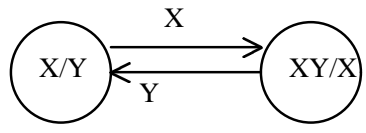

Country 1

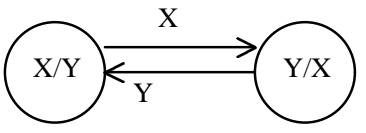

Country 1
Country 2

Structure A

Structure $\mathrm{Bb}$

Structure C

Figure 1. Configurations and Structures

\subsection{General equilibrium and its comparative statics}

In a general equilibrium of the world each individual maximizes utility at a given set of prices with respect to different configurations and quantities of production, trade, and consumption and the set of prices clears the market.

The individuals make their utility maximization decisions based on the infra-marginal analysis. The infra-marginal analysis is that for each configuration, individuals apply marginal analysis to solve for the optimum quantities of consumption, production and trade, and then apply total cost-benefit analysis to compare their utility across all configurations and choose the configuration that gives the highest utility ${ }^{5}$.

\footnotetext{
${ }^{5}$ The essence of the infra-marginal approach can be found in Coase $(1946,1960)$. Coase (1946) noted "a consumer does not only have to decide whether to consume additional units of a product; he has also to decide whether it is worth his while to consume the product at all rather than spend his money in some other direction" (p.173). Buchanan and Stubblebine (1962) introduced the concept of infra-marginal externality which is an early application of the infra-marginal analysis in welfare economics. Formally, the infra-marginal analysis is associated with nonlinear or linear programming, while marginal analysis is associated with classical mathematical programming. Other applications of the infra-marginal analysis can be found in Arrow, Ng, and Yang (1998), Becker (1981), Dixit (1987, 1989), Grossman and Hart (1986), Rosen (1983), and Yang and Y-K. Ng (1993).
} 
Since the individuals' choice variables $\left(x_{i}, x_{i}{ }^{s}, x_{i}{ }^{d}, y_{i}, y_{i}{ }^{s}, y_{i}{ }^{d}\right)$ are not continuous across configurations, we introduce the concept of corner equilibrium which is defined as a relative price of the two goods and a resource allocation that satisfy (1) for a given structure (which is a combination of all individuals' configurations), each individual maximizes utility at a given relative price, and (2) the relative price clears the market.

The general equilibrium is solved in two steps. First, we solve the corner equilibria for each structure, then we identify the parameter subspace within which each corner equilibrium is the general equilibrium where nobody has incentive to unilaterally deviate from his configuration in this structure.

The corner equilibrium for each structure is solved by first solving the individuals' decision problems to obtain the supply and demand functions for goods $\mathrm{X}$ and $\mathrm{Y}$, and then using the market clearing condition to find the corner equilibrium price. For instance, in Structure Ba, the decision problem for individuals in country 1 is :

$$
\begin{aligned}
& \max _{x_{1}, x_{1}^{s} y_{1}, y_{1}^{d}, l_{1 x}, l_{1 y}} U_{1}=x_{1}^{\beta}\left(y_{1}+k y_{1}{ }^{d}\right)^{1-\beta} \\
& \text { s.t. } \quad x_{1}+x_{1}{ }^{s}=a_{1 x} l_{1 x} \\
& y_{1}=a_{1 y} l_{1 y} \\
& y_{1}{ }^{d}=p x_{1}^{s} \\
& l_{1 x}+l_{1 y}=1
\end{aligned}
$$

The first order conditions imply:

$$
p=a_{1 \mathrm{y}} / k a_{1 \mathrm{x}}, \quad x_{1}=\beta a_{1 \mathrm{x}}, x_{1}{ }^{\mathrm{s}}=a_{1 \mathrm{x}}\left(l_{1 \mathrm{x}}-\beta\right), y_{1}=a_{1 \mathrm{y}}\left(1-l_{1 \mathrm{x}}\right), y_{1}{ }^{\mathrm{d}}=a_{1 \mathrm{y}}\left(l_{1 \mathrm{x}}-\beta\right) / k \text {, }
$$

where $p \equiv p_{x} / p_{y}$ is the price of $\mathrm{X}$ in terms of $\mathrm{Y}$.

The decision problem for individuals in country 2 is : 
$\max _{x_{2}^{d} y_{2}, y_{2}{ }^{s}} U_{2}=\left(k x_{2}{ }^{d}\right)^{\beta} y_{2}{ }^{1-\beta}$

s.t. $\quad y_{2}+y_{2}^{s}=a_{2 y}$

$$
y_{2}^{s}=p x_{2}^{d}
$$

The first order conditions imply:

$x_{2}{ }^{d}=\frac{k a_{2 y} a_{1 x}}{a_{1 y}} \beta$

$y_{2}=(1-\beta) a_{2 y}$

$y_{2}{ }^{s}=\beta a_{2 y}$

From the market clearing condition $M_{1} x_{1}{ }^{s}=M_{2} x_{2}{ }^{d}$, we obtain: $l_{1 x}=\left(M_{2} \beta k a_{2 y}\right) / M_{1} a_{1 y}+\beta$, which is less than 1 if and only if $a_{2 y} / a_{1 y}<M_{1}(1-\beta) / k M_{2} \beta$. That is, Structure $\mathrm{Ba}$ is chosen only if $a_{2 y} / a_{1 y}<M_{1}(1-\beta) / k M_{2} \beta$.

The corner equilibria for Structure $\mathrm{A}, \mathrm{Bb}$ and $\mathrm{C}$ are solved using the same approach as above. The results are summarized in Table 1.

Table 1: $\quad$ Corner equilibria

\begin{tabular}{|l|l|l|l|l|}
\hline Structure & $\begin{array}{l}\text { Price } \\
\left(p_{x} / p_{y}\right)\end{array}$ & $\begin{array}{l}\text { Relevant Parameter } \\
\text { Subspace }\end{array}$ & \multicolumn{2}{l|}{ Individual Utility } \\
\cline { 3 - 5 } & & & Country 1 & Country 2 \\
\hline $\mathrm{A}$ & N.A. & $\begin{array}{l}U_{1}(\mathrm{~A}) \equiv\left(\beta a_{1 x}\right)^{\beta} \\
{\left[(1-\beta) a_{1 y}\right]^{1-\beta}}\end{array}$ & $\begin{array}{l}U_{2}(\mathrm{~A}) \equiv\left(\beta a_{2 x}\right)^{\beta} \\
{\left[(1-\beta) a_{2 y}\right]^{1-\beta}}\end{array}$ \\
\hline $\mathrm{Ba}$ & $a_{1 y} / k a_{1 x}$ & $\begin{array}{l}k<k_{1} \equiv M_{1} a_{1 y}(1- \\
\beta) / \beta M_{2} a_{2 y}<1\end{array}$ & $\begin{array}{l}U_{1}(A) \\
U_{2}(\mathrm{~A}) \\
\left(k^{2} a_{2 y} a_{1 x} / a_{2 x} a_{1 y}\right)^{\beta}\end{array}$ \\
\hline $\mathrm{Bb}$ & $k a_{2 y} / a_{2 x}$ & $\begin{array}{l}k<k_{2} \equiv M_{2} a_{2 x} \beta /(1- \\
\beta) M_{1} a_{1 x}<1\end{array}$ & $\begin{array}{l}U_{1}(\mathrm{~A}) \\
\left(k^{2} a_{2 y} a_{1 x} / a_{2 x} a_{1 y}\right)^{1-\beta}\end{array}$ & $U_{2}(A)$ \\
\hline $\mathrm{C}$ & $\beta M_{2} a_{2 y}$ & & $\begin{array}{l}U_{1}(\mathrm{~A})\left[\beta k M_{2} a_{2 y}\right. \\
\left.\div M_{1} a_{1 y}(1-\beta)\right]^{1-\beta}\end{array}$ & $\begin{array}{l}U_{2}(\mathrm{~A})\left[(1-\beta) k M_{1} a_{1 x}\right. \\
\left.\div M_{2} a_{2 x} \beta\right]^{\beta}\end{array}$ \\
\hline
\end{tabular}


Now, we apply the definition of general equilibrium to find out under what conditions each of the structures listed in table 1 occurs in general equilibrium. ${ }^{6}$ Consider structure Ba first. Structure $\mathrm{Ba}$ is the general equilibrium structure if the following three conditions hold. First, under the corner equilibrium relative price in this structure $p=a_{1 y} / k a_{1 x}$, individuals in country 2 prefer specialization in $\mathrm{Y}$ (configuration $\mathrm{Y} / \mathrm{X}$ ) to the alternatives, namely autarky (configuration A) and specialization in $\mathrm{X}$ (configuration $\mathrm{X} / \mathrm{Y}$ ). In other words, the following conditions hold:

$$
\begin{aligned}
& U_{2}(\mathrm{Y} / \mathrm{X}) \geq U_{2}(\mathrm{~A}) \text { which holds iff } k \geq k_{0} \equiv\left[\left(a_{2 x} / a_{2 y}\right) /\left(a_{1 x} / a_{1 y}\right)\right]^{0.5}, \\
& U_{2}(\mathrm{Y} / \mathrm{X}) \geq U_{2}(\mathrm{X} / \mathrm{Y}) \text { which holds iff } k \geq k_{3} \equiv\left[\left(a_{2 x} / a_{2 y}\right) /\left(a_{1 x} / a_{1 y}\right)\right]^{0.5 / \beta} .
\end{aligned}
$$

Second, general equilibrium requires that all individuals in country 1 prefer configuration XY/Y to the alternatives, that is,

$$
\begin{aligned}
& U_{1}(\mathrm{XY} / \mathrm{Y}) \geq U_{1}(\mathrm{X} / \mathrm{Y}) \text { which holds iff } a_{1 y} / a_{1 x} \geq k p=a_{1 y} / a_{1 x} \\
& U_{1}(\mathrm{XY} / \mathrm{Y}) \geq U_{1}(\mathrm{Y} / \mathrm{X}) \text { which holds iff } 1 \geq k .
\end{aligned}
$$

Third, no individual in country 1 is completely specialized in X, i.e.,

$$
l_{1 \mathrm{x}}<1 \text {, which holds iff } k<k_{1} \equiv a_{1 y} M_{1}(1-\beta) / a_{2 \mathrm{y}} M_{2} \beta \text {. }
$$

As $k_{3} \geq k_{0}$, it follows that conditions (1)-(3) hold if $k \in\left(k_{0}, k_{1}\right)$. Since $k_{0}<k_{1}$ holds iff $M_{1}(1-\beta) / M_{2} \beta$ $>\left[\left(a_{2 x} a_{2 y}\right) /\left(a_{1 x} a_{1 y}\right)\right]^{0.5}$, the corner equilibrium in structure $\mathrm{Ba}$ is the general equilibrium if $k \in\left(k_{0}\right.$, $\left.k_{1}\right)$ and $M_{1}(1-\beta) / M_{2} \beta>\left[\left(a_{2 x} a_{2 y}\right) /\left(a_{1 x} a_{1 y}\right)\right]^{0.5}$, where $k_{1} \equiv a_{1 y} M_{1}(1-\beta) / a_{2 y} M_{2} \beta$.

Similarly, we can identify the conditions for other structures to occur in general equilibrium. These conditions are summarized in Table 2.

\footnotetext{
${ }^{6}$ It can be shown that in a structure where the countries export their comparative disadvantage good individuals have incentive to deviate from their configurations in this structure.
} 


\section{Table 2 General equilibrium}

\begin{tabular}{|l|l|l|l|l|l|}
\hline Parameter & $k<k_{0}$ & \multicolumn{4}{|c|}{$k>k_{0}$} \\
\cline { 3 - 6 } Subspaces & & $\frac{M_{1}}{M_{2}}>\left(\frac{a_{2 x} a_{2 y}}{a_{1 x} a_{1 y}}\right)^{\frac{1}{2}} \frac{\beta}{1-\beta}$ & $\frac{M_{1}}{M_{2}}<\left(\frac{a_{2 x} a_{2 y}}{a_{1 x} a_{1 y}}\right)^{\frac{1}{2}} \frac{\beta}{1-\beta}$ \\
\cline { 3 - 7 } & $k \in\left(k_{0}, k_{1}\right)$ & $k \in\left(k_{1}, 1\right)$ & $k \in\left(k_{0}, k_{2}\right)$ & $k \in\left(k_{2}, 1\right)$ \\
\hline $\begin{array}{l}\text { General } \\
\begin{array}{l}\text { Equilibrium } \\
\text { Structure }\end{array}\end{array}$ & $\mathrm{A}$ & $\mathrm{Ba}$ & $\mathrm{C}$ & $\mathrm{Bb}$ & $\mathrm{C}$ \\
\hline
\end{tabular}

where $k_{0} \equiv\left(\frac{a_{1 y} a_{2 x}}{a_{2 y} a_{1 x}}\right)^{\frac{1}{2}}, \quad k_{1} \equiv \frac{M_{1} a_{1 y}(1-\beta)}{M_{2} a_{2 y} \beta}, \quad k_{2} \equiv \frac{M_{2} a_{2 x} \beta}{M_{1} a_{1 x}(1-\beta)}$

It is clear from Table 2 that given the parameter values, the general equilibrium is unique.

Given $k<k_{0}$ the general equilibrium structure is autarky (Structure A). Given $k>k_{0}$ and $M_{1} / M_{2}>\left(a_{2 x} a_{2 y} / a_{1 x} a_{1 y}\right)^{0.5}[\beta /(1-\beta)]$, the general equilibrium structure is Structure Ba if $k<k_{1}$, and is Structure $C$ if $k \in\left(k_{1}, 1\right]$. Given $k>k_{0}$ and $M_{1} / M_{2}<\left(a_{2 x} a_{2 y} / a_{1 x} a_{1 y}\right)^{0.5}[\beta /(1-\beta]$, the general equilibrium is Structure $\mathrm{Bb}$ if $k<k_{2}$, and is Structure $\mathrm{C}$ if $k \in\left(k_{2}, 1\right]$.

A couple of interesting observations can be made from Table 1 and Table 2. Firstly, the general equilibrium market price may not be consistent with the conventional marginal cost pricing rule. When Structure $\mathrm{Ba}$ (or $\mathrm{Bb}$ ) is the general equilibrium structure, the market price of good $\mathrm{X}$ in terms of good $\mathrm{Y}$ equals country 1's (or country 2's) marginal opportunity cost including transaction costs. When Structure $\mathrm{C}$ is the general equilibrium structure, the market price of good $\mathrm{X}$ in terms of good $\mathrm{Y}$ is determined by the total demand and supply in both counties and does not equal either country's marginal opportunity cost of producing X. This observation substantiates Coase's (1946) argument that one should use total cost-benefit analysis in addition to marginal analysis in price determination. 
Secondly, we notice that under certain conditions, only when both countries have absolute advantage in their comparative advantage goods, can Structure $\mathrm{C}$ be the general equilibrium structure. For instance, if $\left[M_{1}(1-\beta)\right] /\left(M_{2} \beta\right)=1$ (which holds if, but not only if, both countries are of similar size and consumers' preference for both goods are similar), we have $k_{1}=a_{1 y} / a_{2 y}$. Since $k \in(0,1), k>k_{1}$ can be satisfied only if $a_{2 y}>a_{1 y}$. As $k_{1}$ is relevant within the parameter subspace, $M_{1} / M_{2}>\left(a_{2 x} a_{2 y} / a_{1 x} a_{1 y}\right)^{0.5}[\beta /(1-\beta)]$, which becomes $\left(a_{2 x} a_{2 y}\right) /\left(a_{1 x} a_{1 y}\right)<1$ when $\left[M_{1}(1-\beta)\right] /\left(M_{2} \beta\right)=1$. For $k>k_{1}$ to hold within this parameter subspace, it is necessary that $a_{1 x}>a_{2 x}$. Therefore, if $\left[M_{1}(1-\beta)\right] /\left(M_{2} \beta\right)=1$ and $\left(a_{2 x} a_{2 y}\right) /\left(a_{1 x} a_{1 y}\right)<1$, complete division of labor can occur in general equilibrium only if both countries have absolute advantage in their comparative advantage good. A similar result can be found in Chipman $(1965,1979)$ although his models did not incorporate positive transaction costs.

We can conduct two types of comparative static analyses of the general equilibrium. The first type is the conventional comparative static analysis for a given structure - the equilibrium price, quantities of goods and the numbers of individuals selling different goods change continuously in response to a continuous change in parameters.

The second type of comparative static analysis examines how changes in parameters generate shifts of the general equilibrium across corner equilibria. It shows that the general equilibrium price, quantities and indirect utility functions can discontinuously jump between corner equilibria as parameters reach some critical values. Suppose the general equilibrium is initially at Structure A, as the transaction efficiency coefficient $(k)$ increases from a low value to $k_{0}$, and then to $k_{1}$ or $k_{2}$, the general equilibrium jumps from autarky to partial division of labor, 
and then to complete division of labor. Whether the transitional structure is $\mathrm{Ba}$ or $\mathrm{Bb}$ depends on the relative size and relative productivity of the two countries, and individuals' relative preference over the two goods. For instance, if country 1 is relatively large in size (large $M_{1} / M_{2}$ ), its relative productivity is high (large $a_{1 x} a_{1 y} / a_{2 x} a_{2 y}$ ), and the consumer's relative preference is in favor of its comparative disadvantage good $\mathrm{Y}$ (large $(1-\beta) / \beta$ ), then country 1 is likely to produce both goods $\mathrm{X}$ and $\mathrm{Y}$, and the general equilibrium structure will be structure Ba. As the general equilibrium pattern of division of labor changes, the equilibrium price also changes discontinuously, so do individuals' utility levels. Note that all critical values of $k$ that demarcate different structures are functions of relative population size, relative tastes, and relative production condition. For instance, $k_{0}$ is a decreasing function of the degree of comparative advantage $\left(a_{1 x} / a_{1 y}\right) /\left(a_{2 x} / a_{2 y}\right), k_{1}$ is a decreasing function of relative taste $\beta /(1-\beta)$ and an increasing function of relative population size, $M_{1} / M_{2}$, and the relative productivity of good $\mathrm{y}$, $a_{1 y} / a_{2 y}$. Hence, the inframarginal comparative statics of general equilibrium completely partition the eight-dimension $\left(\beta, a_{1 x}, a_{1 y}, a_{2 x}, a_{2 y}, M_{1}, M_{2}, k\right)$ parameter space into subspaces within which particular corner equilibria are general equilibria. They rigorously identify the degree of substitution between the parameters representing transaction conditions, production conditions, and tastes for a shift of the general equilibrium from a structure to another. For instance, for a given degree of comparative advantage, a sufficiently great increase in transaction efficiency will generate a jump of the general equilibrium from autarky to the partial division of labor; while for a given transaction efficiency, a sufficiently great increase in the degree of comparative advantage will shift the general equilibrium from autarky to the partial division of labor too. In this sense, our inframarginal comparative statics are much more than the statement that a better 
transaction condition will generate a higher level of division of labor, which sounds like tautology.

From the above analysis, we conclude:

Proposition 1 The general equilibrium structure is determined by the level of transaction efficiency, the relative productivity and relative population size of the two countries, and individuals' relative preference over the two goods. Given other parameters, improvements in transaction efficiency can make the general equilibrium structure jump from autarky to partial division of labor and then to complete division of labor.

Proposition 1 implies that transaction efficiency plays an important role in determining the size of the market, and the size of the market in turn determines the equilibrium pattern and level of the division of labor. Thus, we have formalized Smith's (1776) conjecture that the division of labor is limited by the extent of the market, and the extent of the market is determined by transportation costs.

It is interesting to note that in our model, an increase in transaction efficiency coefficient (k) can increase total transaction costs because the increase in $k$ can generate a jump of the general equilibrium from a low level of division of labor to a higher level, thus increasing the total number of transactions. This implication can be used to explain why the income share of transaction costs has increased as transaction efficiency improves (North, 1986).

\section{A $2 \times 2$ Ricardian model with tariff}

Based on the model in section 2, suppose that country $i(i=1,2)$ imposes an ad valorem tariff of rate $t_{i}$, and transfer all tariff revenue equally to all individuals in country $i$. In the case, individuals' budget constraint changes, for instance in configuration $\mathrm{X} / \mathrm{Y}$, from $p_{\mathrm{x} x}{ }^{\mathrm{s}}=p_{\mathrm{y} y}{ }^{\mathrm{d}}$ to $p_{\mathrm{x} x}^{\mathrm{s}}$ 
$+r=(1+t) p_{\mathrm{y} y}^{\mathrm{d}}$ where $r$ is transfer of tariff revenue from the government to an individual. Individuals take the amount of transfer as given. At equilibrium, the amount of transfer equals tariff revenue. Also, we assume that the transaction efficiency coefficient for country i is $k_{\mathrm{i}}$, which may be different between countries. Using the same procedure as in section 2, we can solve for the corner equilibrium for each structure. The corner equilibrium solutions are presented in Table 3 .

It is easy to see that if $t_{1}=t_{2}=0$ and $k_{1}=k_{2}$, Table 3 reduces to Table 1 . If $t_{1}=t_{2}=0$, the textbook Ricardian model predicts that the "large" country which produces both goods does not get any gains from trade. This result can be clearly seen from Table 1 -- when the general equilibrium occurs in structure $\mathrm{Ba}$ (or $\mathrm{Bb}$ ), individuals in country 1 (or country 2) which produces both goods $\mathrm{X}$ and $\mathrm{Y}$ get the same level of utility as they do in autarky.

Table 3: $\quad$ Corner equilibrium solutions

\begin{tabular}{|c|c|c|c|c|}
\hline \multirow[t]{2}{*}{ Structure } & \multirow{2}{*}{$\begin{array}{l}\text { Price } \\
\left(p_{x} / p_{y}\right)\end{array}$} & \multirow{2}{*}{$\begin{array}{l}\text { Relevant } \\
\text { Parameter } \\
\text { Subspace }\end{array}$} & \multicolumn{2}{|l|}{ Individual Utility } \\
\hline & & & Country 1 & Country 2 \\
\hline $\mathrm{A}$ & N.A. & & $\begin{array}{l}\left(\beta a_{1 x}\right)^{\beta}\left[(1-\beta) a_{1 y}\right]^{1-\beta} \\
\equiv U_{1}(A)\end{array}$ & $\begin{array}{l}\left(\beta a_{2 x}\right)^{\beta}\left[(1-\beta) a_{2 y}\right]^{1-\beta} \\
\equiv U_{2}(A)\end{array}$ \\
\hline $\mathrm{Ba}$ & $\begin{array}{l}\left(1+t_{1}\right) \\
a_{1 y} / k_{1} a_{1 x}\end{array}$ & $\begin{array}{l}k_{1}<\left(M_{1} / M_{2}\right) \\
{[(1-\beta) / \beta]} \\
\left(a_{1 y} / a_{2 y}\right) D_{1}\end{array}$ & $\begin{array}{l}{\left[\left(1+L_{1 x} t_{1}\right) /\left(1+\beta t_{1}\right)\right]} \\
U_{1}(A)\end{array}$ & $\begin{array}{l}{\left[k_{1} k_{2}\left(a_{1 x} a_{2 y}\right) /\left(a_{1 y} a_{2 x}\right)\right]^{\beta}} \\
T_{1}^{\beta} U_{2}(A)\end{array}$ \\
\hline $\mathrm{Bb}$ & $\begin{array}{l}k_{2} a_{2 y} / \\
{\left[a_{2 x}\left(1+t_{2}\right)\right]}\end{array}$ & $\begin{array}{l}k_{2}<\left(M_{2} / M_{1}\right) \\
{[\beta /(1-\beta)]} \\
\left(a_{2 x} / a_{1 x}\right) D_{2}\end{array}$ & $\begin{array}{l}{\left[k_{1} k_{2}\left(a_{1 x} a_{2 y}\right) /\left(a_{1 y} a_{2 x}\right)\right]^{1-\beta}} \\
T_{2}^{1-\beta} U_{1}(A)\end{array}$ & $\begin{array}{l}{\left[\left(1+t_{2}-t_{2} L_{2 x}\right) /\right.} \\
\left.\left(1+t_{2}-\beta t_{2}\right)\right] U_{2}(A)\end{array}$ \\
\hline $\mathrm{C}$ & $\begin{array}{l}\left(M_{2} / M_{1}\right) \\
{[\beta /(1-\beta)]} \\
\left(a_{2 y} / a_{1 x}\right) \\
{\left[\left(1+\beta t_{1}\right) /\right.} \\
\left(1+(1-\beta) t_{2}\right]\end{array}$ & & $\begin{array}{l}\left\{\left(k_{1} M_{2} / M_{1}\right)\right. \\
{[\beta /(1-\beta)]} \\
\left.\left(a_{2 y} / a_{1 y}\right)\right\}^{1-\beta} T_{3}{ }^{1-\beta} U_{1}(A)\end{array}$ & $\begin{array}{l}\left\{\left(k_{2} M_{1} / M_{2}\right)\right. \\
{[(1-\beta) / \beta]} \\
\left.\left(a_{1 x} / a_{2 x}\right)\right\}^{\beta} T_{4}{ }^{\beta} U_{2}(A)\end{array}$ \\
\hline
\end{tabular}


where $D_{1} \equiv\left(1+t_{1}\right)\left[1+(1-\beta) t_{2}\right] /\left(1+\beta t_{1}\right)$

$D_{2} \equiv\left(1+\beta t_{1}\right)\left(1+t_{2}\right] /\left[\left(1+(1-\beta) t_{2}\right)\right.$

$L_{1 x}=\beta+\left(M_{1} / M_{2}\right)\left(k_{1} \beta a_{2 y} / a_{1 y}\right)\left\{\left(1+\beta t_{1}\right) /\left[\left(1+t_{1}\right)\left[1+t_{2}-\beta t_{2}\right]\right\}>\beta\right.$

$T_{1} \equiv\left[\left(1+t_{1}\right)\left(1+t_{2}-\beta t_{2}\right)\right]^{-1}\left[\left(1+t_{2}\right) /\left(1+t_{2}-\beta t_{2}\right)\right]^{(1-\beta) / \beta}$

$L_{2 x}=\beta-\left(M_{1} / M_{2}\right)\left[k_{2}(1-\beta) a_{2 x} / a_{1 x}\right]\left\{\left(1+t_{2}-\beta t_{2}\right) /\left[\left(1+\beta t_{1}\right)\left(1+t_{2}\right)\right\}<\beta\right.$

$T_{2} \equiv\left[\left(1+t_{2}\right)\left(1+\beta t_{1}\right)\right]^{-1}\left[\left(1+t_{1}\right) /\left(1+\beta t_{1}\right)\right]^{\beta /(1-\beta)}$

$T_{3} \equiv\left(1+t_{2}-\beta t_{2}\right)^{-1}\left[\left(1+t_{1}\right) /\left(1+\beta t_{1}\right)\right]^{\beta /(1-\beta)}$

$T_{4} \equiv\left(1+\beta t_{1}\right)^{-1}\left[\left(1+t_{2}\right) /\left(1+t_{2}-\beta t_{2}\right)\right]^{(1-\beta) / \beta}$

The story is different when tariff is introduced. Refer to Table 3, if the general equilibrium occurs in Structure $\mathrm{Ba}$ (or $\mathrm{Bb}$ ), individuals in the country producing both goods, gets a higher utility than they do in Autarky. Moreover, in Structure Ba, $\partial U_{1} / \partial t_{1}>0$ (or in Structure $\left.\mathrm{Bb}, \partial U_{2} / \partial t_{2}>0\right)$, that is, given the tariff rate of the country producing one good, the country producing two goods can improve its own welfare by raising its tariff rate. This is because the latter country determines the terms of trade, and it can improve its terms of trade by imposing a tariff, thereby obtaining a larger share of the gains from trade. The gain of the country producing two goods is at the expense of its trading partner as can be shown that $\partial U_{2} / \partial t_{1}<0$ in Structure Ba and $\partial U_{1} / \partial t_{2}<0$ in Structure Bb. If the country producing two goods imposes a sufficiently high tariff, the other country may want to withdraw from trade, in which case both countries are hurt.

In contrast to the country producing two goods, the completely specialized country has no influence on the term of trade. As a result, it only hurts itself by imposing a tariff, as can be derived from Table 3, $\partial U_{2} / \partial t_{2}<0$ in Structure $\mathrm{Ba}$ and $\partial U_{1} / \partial t_{1}<0$ in Structure $\mathrm{Bb}$.

If both countries can influence the terms of trade (as in Structure C), then the gains of trade are shared between the two countries. However, since $\partial U_{1} / \partial t_{1}>0$ and $\partial U_{2} / \partial t_{2}>0$ in structure C, i.e., each country can benefit from raising its own tariff given the other country's tariff rate, each country will be tempted to raise its own tariff as much as possible. But if they 
both raise tariff, both can be worse off. It can be shown that in Structure $\mathrm{C} \partial U_{1} / \partial t_{2}<0$ and $\partial U_{2} / \partial t_{1}<0$, and that $U_{1}$ converges to 0 as $t_{2}$ tends to infinity and $U_{2}$ converges to 0 as $t_{1}$ tends to infinity. This implies that as a country sufficiently increases its tariff, the other country will not only be marginally worse off, but also discontinuously (inframarginally) jump from trade to autarky.

The above analysis is conducted within the Walrasian regime. To analyze the behavior of the governments in the two countries, we examine two other regimes: a Nash game and a Nash tariff bargaining game.

First suppose the governments in the two countries play a Nash game. Each government chooses its own tariff rate to maximize home resident's utility, taking as given the tariff rate in the foreign country and the Walrasian decisions of all individuals. For each structure $(\mathrm{A}, \mathrm{Ba}, \mathrm{Bb}$ or C), a Nash corner equilibrium can be calculated. The Nash general equilibrium is one of four Nash corner equilibria. Consider structure Ba first. Since $\partial U_{2} / \partial t_{2}<0$ in this structure, the equilibrium strategy of country 2 's government is to impose zero tariff. Since $\partial U_{1} / \partial t_{1}>0$ and $\partial U_{2} / \partial t_{1}<0$, the equilibrium strategy of country 1 's government is to impose a tariff as high as possible provided each individual in country 2 will not deviate from configuration Y/X. If the Nash corner equilibrium in structure $\mathrm{Ba}$ is the Nash general equilibrium, each individual in country 2 is slightly better off than in autarky and most gains from trade go to country 1 . In other words, the Nash corner equilibrium in the tariff game in this structure generates a distribution pattern of gains from trade that is opposite to the distribution in the absence of a tariff where all the gains go to country 2 .

This Nash corner equilibrium is not Pareto optimal because of the deadweight loss caused by tariff. But the distortion caused by the tariff converges to zero as gains from trade net of 
transaction costs go to zero. If each government can choose any level of tariff (including zero tariff), the Walrasian equilibrium with no tariff will not occur when structure $\mathrm{Ba}$ is chosen in general equilibrium because country 1's government has an incentive to deviate from that equilibrium by increasing tariff.

Since structure $\mathrm{Bb}$ is symmetric to $\mathrm{Ba}$, we can obtain a similar result: a tariff game will reverse the distribution pattern of gains from trade and generate distortions.

Now consider structure C. Since $\partial U_{1} / \partial t_{1}>0, \partial U_{2} / \partial t_{1}<0, \partial U_{1} / \partial t_{2}<0, \partial U_{2} / \partial t_{2}>0$ in this structure, the Nash corner equilibrium strategy of each government in this structure is to impose a tariff as high as possible provided the individuals in the other country will not deviate from their configurations in this structure. This implies that the gains from the complete division of labor in this structure will be almost exhausted by the deadweight loss caused by the tariff war. If the Nash general equilibrium occurs in this structure, this equilibrium may generate very significant welfare loss to both countries. This is a typical prisoners' dilemma.

Now suppose the two governments play a Nash tariff bargaining game. This game maximizes a Nash product of the net gains of the two countries with respect to tariff rates of the two countries. Each country's net gain is the difference between each individual's realized utility and her utility at a disagreement point. The Nash tariff negotiation equilibrium can be solved in two steps: (1) a restricted Nash bargaining equilibrium is solved for a given structure, taking another structure as a disagreement point; (2) the two governments bargain over choice of structure.

The Nash product in structure $\mathrm{C}$ is

$$
V=V_{1} V_{2}=\left[U_{1}(\mathrm{C})-U_{1}(\mathrm{~A})\right]\left[U_{2}(\mathrm{C})-U_{2}(\mathrm{~A})\right]
$$


where $U_{\mathrm{i}}(\mathrm{C})$ and $U_{\mathrm{i}}(\mathrm{A})$ are given in Table 3 . The Nash bargaining corner equilibrium in structure $\mathrm{C}$ is given by maximizing $V$ with respect to $t_{1}$ and $t_{2}$. The two first order conditions $\partial V / \partial t_{1}=$ $\partial V / \partial t_{2}=0$ generate $\left(1+t_{1}\right)\left(1+t_{2}\right)=1$. Hence, the solution of the Nash tariff negotiation game is $t_{1} *$ $=t_{2}{ }^{*}=0$. This implies that the Nash tariff negotiation will generate a bilateral laissez faire regime. But this laissez faire regime cannot be achieved in the absence of tariff negotiation because of prisoners' dilemma.

Although in this Nash bargaining game, no risk is specified, the players' attitude towards risk "plays a central role" (Osborne and Rubinstein, 1990, p.10). As long as there exists uncertainty about other players' behavior, there is chance that the negotiation breaks down. Thus each player intends to maximize her expected utility gain in the negotiation. In fact, the Nash product can be interpreted as a player's expected utility gain, with the probability of reaching an agreement being approximated by the utility gain(s) of the other player(s). According to this view of Nash (1950), the Nash bargaining solution is the outcome of a noncooperative game despite the fact that the gains are shared fairly among players.

If each government can decide whether or not to participate in a tariff negotiation game, then it is clear that when structure $\mathrm{Ba}$ or $\mathrm{Bb}$ occurs in general equilibrium, it must be a Nash equilibrium with no tariff negotiation since the country producing two goods can get most of the gains from unilateral tariff. When structure $\mathrm{C}$ occurs in general equilibrium, the general equilibrium must involve tariff negotiation since both governments prefer tariff negotiation to tariff war -- clearly, the two countries receive more net gains in the tariff negotiation game than in the tariff war since the Nash tariff bargaining equilibrium, which coincides with the Walrasian equilibrium with not tariff, is Pareto optimal. 
This result explains why it is difficult to realize laissez faire regimen even if it is good for all countries. When sovereignty of a country can be used to seek rent in international trade via taxation power, coordination difficulty in a prisoners' dilemma makes tariff negotiation essential for fully exploiting mutually beneficial gains from trade. Following the method in the previous section, we can show that in the model with endogenous choice of regimes, the general equilibrium discontinuously jumps from autarky to structure $\mathrm{Ba}$ or $\mathrm{Ba}$, then to structure $\mathrm{C}$ as the transaction efficiency coefficient $k$ increases.

Summarizing the above analysis, we have:

Proposition 2 In a model with the two governments which can choose tariff level and decide whether or not to participate in tariff negotiations, if partial division of labor occurs in equilibrium, it is a Nash tariff equilibrium with no tariff negotiation. Most gains from trade go to the country producing both goods. If complete division of labor occurs in equilibrium, it is a Nash tariff negotiation equilibrium which generates bilateral laissez faire regime.

Proposition 2 may be used to explain two phenomena. First, despite the distortions caused by tariff, tariff may be used by a government to get a larger share of gains from trade since the Walrasian equilibrium with no tariff may divide gains to trade very unequally between countries. Second, when transaction condition is not very good so that the equilibrium is associated with an intermediate level of division of labor, some countries (which do not completely specialize) may prefer a unilateral tariff, whereas other countries (which completely specialize) may prefer a unilateral laissez faire regime. But as transaction conditions improve, all countries may prefer tariff negotiations to a unilateral tariff or a unilateral laissez faire regime.

In the $16^{\text {th }}$ and $17^{\text {th }}$ century, unilateral tariff was advocated by Mercantilists as a means of rent seeking in international trade (see for instance Ekelund and Tollison, 1981). It gave way to 
trade liberalization in the $18^{\text {th }}$ and $19^{\text {th }}$ century in some European countries. However, even after World War II, many governments in developing countries still adopted unilateral tariff protection. More recently, tariff negotiations have become increasingly prevalent. Some economists use the Walrasian model to explain the emergence of laissez faire regime, but the model cannot explain why other trade regimes persisted in many countries for a long period of time. Other economists use the theory of import substitution and export substitution to explain the transition from unilateral tariff to trade liberalization (see, for instance, Balassa, 1980 and Bruton, 1998), but the theory cannot explain why laissez faire regime was unstable even between developed countries; why some countries prefer unilateral protection tariff and others prefer laissez faire regime; and why tariff negotiations may be necessary for the exploitation of the gains from trade. Proposition 2 in this paper seems to offer a more plausible explanation as to why unilateral tariff prevailed in the early stage of economic development; why trade liberalization is preferred in later stages of economic development; why unilateral tariff and unilateral laissez faire regime coexist, and under what condition tariff negotiation is essential for the exploitation of gains from trade.

\section{A 3x2 Ricardian Model}

In this section, we extend the simple $2 \times 2$ Ricardian model to include a third country, country 3. It is assumed that transaction conditions are different from country to country such that $k_{1}, k_{3}>k_{2}$, where $k_{i}$ is the transaction efficiency coefficient in country i. We intend to show that a country which does not have a comparative advantage to the other two countries and/or which has low transaction efficiency can be excluded from trade. 
Suppose that the production functions in country $i(i=1,2,3)$ are the same as in subsection 2.1 and that $\left(a_{3 x} / a_{3 y}\right)<\left(a_{2 x} / a_{2 y}\right)<\left(a_{1 x} / a_{1 y}\right)$, i.e., country 1 has a comparative advantage in producing good $\mathrm{X}$ to the other two countries, country 2 has a comparative advantage in producing $\mathrm{X}$ relative to country 3 , and a comparative advantage in producing good $\mathrm{Y}$ relative to country 1; and country 3 has a comparative advantage in producing $\mathrm{Y}$ to the other two countries.

We consider only the case where the trading countries are completely specialized. For similar reasons discussed in subsection 2.2, all structures involving trade in comparative disadvantage goods cannot occur in general equilibrium. We now prove that if a structure which involves trading between only two of the three countries, the two trading countries must be country 1 and country 3 . In other words, the country which has the lowest transaction efficiency and/or has no comparative advantage to the other two countries may be excluded from trade.

Suppose only country 1 and country 2 trade. This can occur in general equilibrium only if individuals in country 2 prefer specialization in $\mathrm{Y}$ (or configuration $\mathrm{Y} / \mathrm{X}$ ) to autarky and individuals in country 3 prefer autarky to specialization in Y. That is, the following inequalities hold:

$U_{2}(\mathrm{Y} / \mathrm{X})>U_{2}(\mathrm{~A})$ which holds iff $p<\left(a_{2 y} / a_{2 x}\right) k_{2}$ and

$U_{3}(\mathrm{Y} / \mathrm{X})<U_{3}(\mathrm{~A})$ which holds iff $p>\left(a_{3 y} / a_{3 x}\right) k_{3}$.

where the indirect utility functions for different configurations are from Table 1. The two inequalities jointly imply $\left(a_{2 x} / a_{2 y} k_{2}\right)<\left(a_{3 x} / a_{3 y} k_{3}\right)$ which contradicts the assumption $\left(a_{2 x} / a_{2 y}\right)>\left(a_{3 x} / a_{3 y}\right)$ and $k_{2}<k_{3}$.

Suppose instead only country 2 and country 3 trade. This can occur in general equilibrium only if

$U_{2}(\mathrm{X} / \mathrm{Y})>U_{2}(\mathrm{~A})$ which holds iff $p>a_{2 y} / a_{2 x} k_{2}$ and 
$U_{1}(\mathrm{X} / \mathrm{Y})<U_{1}(\mathrm{~A})$ which holds iff $p<a_{1 y} / a_{1 x} k_{1}$.

The two inequalities jointly imply $\left(a_{1 y} / a_{1 x} k_{1}\right)>\left(a_{2 y} / a_{2 x} k_{2}\right)$ which contradicts the assumption $\left(a_{1 x} / a_{1 y}\right)>\left(a_{2 x} / a_{2 y}\right)$ and $k_{2}<k_{1}$.

Next we examine the conditions under which the structure involving trade between only country 1 and country 3 occurs in general equilibrium. The conditions are:

$U_{1}(\mathrm{X} / \mathrm{Y})>U_{1}(\mathrm{Y} / \mathrm{X})$ which holds iff $p>\left(a_{1 y} / a_{1 x}\right) k_{1}^{2 \beta-1}$,

$U_{1}(\mathrm{X} / \mathrm{Y})>U_{1}(\mathrm{~A})$ which holds iff $p>a_{1 y} / a_{1 x} k_{1}$,

$U_{2}(\mathrm{X} / \mathrm{Y})<U_{2}(\mathrm{~A})$ which holds iff $p<a_{2 y} / a_{2 x} k_{2}$,

$U_{2}(\mathrm{Y} / \mathrm{X})<U_{2}(\mathrm{~A})$ which holds iff $p>\left(a_{2 y} / a_{2 x}\right) k_{2}$,

$U_{3}(\mathrm{Y} / \mathrm{X})>U_{3}(\mathrm{~A})$ which holds iff $p<\left(a_{3 y} / a_{3 x}\right) k_{3}$,

$U_{3}(\mathrm{Y} / \mathrm{X})>U_{3}(\mathrm{X} / \mathrm{Y})$ which holds iff $p<\left(a_{3 y} / a_{3 x}\right) k_{3}^{2 \beta-1}$,

where $p=a_{3 y} M_{3} \beta / a_{1 x} M_{1}(1-\beta)$ is the corner equilibrium relative price in this structure.

The six inequalities together imply $\operatorname{Min}\left\{a_{2 y} / a_{2 \mathrm{x}} k_{2},\left(a_{3 y} / a_{3 x}\right) k_{3}\right\}>a_{3 y} M_{3} \beta / a_{1 \mathrm{x}} M_{1}(1-\beta)>$ $\operatorname{Max}\left\{a_{1 y} / a_{1 \mathrm{x}} k_{1},\left(a_{2 y} / a_{2 x}\right) k_{2}\right\}$. The parameter subspace satisfying this condition is certainly not empty. For instance, if $k_{2}$ is sufficiently close to 0 and $k_{1}$ and $k_{3}$ are sufficiently close to 1 , then the above condition becomes $\left(a_{3 y} / a_{3 x}\right) k_{3}>a_{3 y} M_{3} \beta / a_{1 \mathrm{x}} M_{1}(1-\beta)>a_{1 y} / a_{1 \mathrm{x}} k_{1}$, or $\left(a_{1 x} / a_{3 x}\right) k_{3}>$ $M_{3} \beta / M_{1}(1-\beta)>a_{1 y} / a_{3 y} k_{1}$, which holds only if $k_{3} k_{1}\left[\left(a_{1 x} / a_{1 y}\right) /\left(a_{3 x} / a_{3 y}\right)\right]>1$. This condition can be satisfied if the relative population size is not too far away from a balance with relative tastes, the two countries' transaction conditions are sufficiently good and the degree of comparative advantage (measured by $\left.\left(a_{1 x} / a_{1 y}\right) /\left(a_{3 x} / a_{3 y}\right)\right)$ between the two countries is great. 
Summarizing the above analysis, we obtain:

Proposition 3 In a $3 \times 2$ Ricardian model within certain parameter subspace, it is possible that the country that has no comparative advantage in producing any good over both of its potential trading partners and/or that has very low transaction efficiency will be excluded from trade.

This proposition can accommodate opinions of both sides in a recent debate on international competitiveness. Krugman (1994) argued that a nation should focus on promoting free trade and that the emphasis on international competitiveness can be "a dangerous obsession". Sachs (1996) and Prestowitz et. al. (1994), on the other hand, contended that international competitiveness plays an essential role in improving national welfare. If international competitiveness is measured by a country's transaction efficiency, then proposition 3 confirms that competitiveness matters. Proposition 3 implies that comparative advantage is not enough for realizing gains from trade. A country can be excluded from trade even if it has comparative advantage to another single country when its transaction efficiency is low or/and it has no comparative advantage to both of the other potential partners. However, the proposition also supports Krugman's argument that a country should focus on promoting free trade and improving transaction efficiency. In our model, the promotion of free trade can be done through reducing tariff and non-tariff barriers of trade so as to improve transaction efficiency $k$. If $k$ is extremely low $\left(k<k_{0}\right)$, no trade occurs and absolute and comparative advantage does not do good for trade. Since in our model the improvement of the transaction efficiency coefficient through trade liberalization policies can generate a jump of general equilibrium from a low to a high level of division of labor, the argument for free trade is even stronger than the conventional marginal analysis suggests. Therefore, international competitiveness and free trade are important factors contributing to a country's welfare. And Krugman's emphasis on trade liberalization is 
particularly relevant if the pursuit of international competitiveness is used as an excuse for impeding free trade.

Introducing tariff into the model in this section, it can be shown that when all governments are allowed to choose tariff level and tariff negotiation and when the partial division of labor occurs in general equilibrium, the country with a higher tariff and/or worse transaction condition (a small value of $k$ ) will be excluded from trade. Hence, in a world economy with many governments, even in the partial division of labor, tariff rates will be reduced by competition between the governments in those similar countries. Since a greater value of $k$ will increase the number of countries that are involved in international trade, which will in turn ensure a multilateral free trade regime even if the partial division of labor occurs in general equilibrium, a sufficiently great increase in $k$ in the country that was excluded from trade can then ensure a zero tariff rate for all countries even if the general equilibrium is associated with the partial division of labor. This result implies that there are two possible explanations for a shift of trade regime from protection tariff to trade liberalization. The first is to attribute such a shift to the increase in the level of division of labor (a shift from the partial division of labor to the complete division of labor), which is caused by improvements in transaction conditions. The second is to attribute such a shift to the increase in the number of countries that are involved in international trade, which is caused by improvements of the transaction conditions in those countries which used to be excluded from trade. Since an increase in $k$ can be generated either by improvements in transportation conditions (the emergence of new transportation technology or the development of transportation infrastructure) or by institutional changes (the emergence of a legal system that more effectively protects property rights or a more competitive and efficient 
banking system), we can explain this shift of trade regime by improvements of transportation and institution environment.

\section{Conclusion}

In this paper, we have studied a general equilibrium $2 \times 2$ Ricardian model using the inframarginal analysis. Departing from the neoclassical paradigm where individuals' levels of specialization are not endogenized, we explain international trade by individuals' choices of their levels and patterns of specialization. In our analysis, the traditional rule of marginal cost pricing may not be applicable; and the comparative statics involve discontinuous jumps -- as transaction efficiency improves, the general equilibrium structure may jump from autarky to partial division of labor and then to complete division of labor. This prediction is supported by historical evidences documented in North (1958) and North and Weingast (1989) and by empirical evidences provided in Barro (1997), Easton and Walker (1997), Frye and Shleifer (1997), Gallup and Sachs (1998), Sachs and Warner (1995, 1997).

We have also examined some effects of tariff when the government can choose tariff level and can decide whether or not to participate in tariff negotiations. If the partial division of labor occurs in equilibrium, then the general equilibrium is associated with unilateral tariff by the country producing both goods and most gains from trade go to this country, while the completely specialized country chooses unilateral laissez faire regime. If the complete division of labor occurs in equilibrium, the equilibrium regime is tariff negotiation which generates bilateral laissez faire regime and fairly divides gains to trade between the two countries. Tariff negotiation is essential for realizing free trade. 
Finally, we have shown that in a $3 \times 2$ model the country that does not have a comparative advantage over both of the other countries and/or that has low transaction efficiency may be excluded from trade.

A logical extension of this paper is to incorporate fixed learning costs and other types of increasing returns to specialization to the Ricardian model. The economies of specialization will generate endogenous comparative advantage (Yang, 1994). It will be interesting to see how exogenous and endogenous comparative advantage interact with each other and what implications such interactions generate. Also, more goods and countries may be introduced into our model to test robustness of our results. 


\section{References}

Arrow, A., Y-K Ng, and X, Yang (1998), Increasing Returns and Economics Analysis, London: Macmillan.

Balassa, B. (1980), The Process of Industrial Development and Alternative Development Strategies, Princeton University, International Finance Section, Essays in International Finance, No. 141.

Barro, R. (1997), Determinants of Economic Growth, Cambridge, MA, MIT Press.

Becker, Gary (1981), A Treatise on the Family, Cambridge, Massachusetts, Harvard University Press.

Bruton, Henry (1998), “A Reconsideration of Import Substitution,” Journal of Economic Literature, 36, 903-36.

Buchanan, James M. and Stubblebine, W. Craig (1962), "Externality,” Economica, 29, 371-84.

Chipman, John (1965), "A Survey of the Theory of International Trade, Part 1, the Classical Theory," Econometrica, 33(3), 477-519.

Chipman, John (1979), “Mill's 'Superstructure’: How Well Does it Stand up?” History of Political Economy, 11(4), 477-504.

Coase, Ronald (1946), “The Marginal Cost Controversy,” Economica, 13, 169-82.

Coase, Ronald (1960), “The Problem of Social Cost,” Journal of Law and Economics, 3, 1-44.

Dixit, A. (1987), "Trade and Insurance with Moral Hazard," Journal of International Economics, 23, 201-20.

Dixit, A. (1989), "Trade and Insurance with Adverse Selection," Review of Economic Studies, 56, 235-48.

Dixit, A. and Norman, V. (1980), Theory of International Trade, Cambridge: Cambridge University Press.

Dornbusch, Rudiger; Fischer, Stanley; Samuelson, Paul A. (1977), "Comparative Advantage, Trade, and Payments in a Ricardian Model with a Continuum of Goods." American Economic Review. 67, 823-39

Ekelund, Robert, and Robert Tollison (1981), Merchantilism as an Rent-seeking Society, College Station, TX, Texas A \& M University Press.

Easton, Stephen and Michael, Walker (1997): "Income, Growth, and Economic Freedom", American Economic Review, Papers and Proceedings, 87, 328-32.

Frye, Timothy and Shleifer, Andrei (1997): "The Invisible Hand and the Grabbing Hand." American Economic Review, Papers and Proceedings, 87, 354-58.

Gallup, John and Jeff Sachs (1998), "Geography and Economic Development," Working Paper, Harvard Institute for International Development.

Gomory, Ralph E. (1994), “A Ricardo Model with Economies of Scale,” Journal of Economic Theory, 62, 394-419.

Grossman, S. and Hart. O (1986), "The Costs and Benefits of Ownership: A Theory of Vertical and Lateral Integration," Journal of Political Economy, 94, 691-719.

Houthakker, H. S. (1976), "The Calculation of Bilateral Trade Patterns in a Ricardian Model with Intermediate Products and Barriers to Trade," Journal of International Economics, 6, 251-288. 
Krugman, Paul (1994), “Europe Jobless, America Penniless?” Foreign Policy, 95, 19-34.

Krugman, Paul (1994), “Competitiveness: A Dangerous Obsession,” Foreign Affairs, 73(2), 28-44.

Nash, J. F. (1950), “The Bargaining Problem,” Econometrica, 18, 115-62.

North, D. (1958), "Ocean Freight Rates and Economic Development", Journal of Economic History, ??, 537-55.

North, D. (1986), "Measuring the Transaction Sector in the American Economy", in S. Eugerman and R. Gallman, eds.,. Long Term Trends in the American Economy, Chicago, University of Chicago Press.

Osborne, Martin J. and Rubinstein, Ariel (1990), Bargaining and Markets, San Diego: Academic Press, Inc.

Prestowitz, Clyde V. Jr et al. (1994), “The Fight over Competitiveness,” Foreign Affairs, 73(4), 186-197.

Ricardo, David (1817), The Principles of Political Economy and Taxation, London: J.M. Dent \& Sons Ltd., 1965.

Rosen, S. (1978), “Substitution and the Division of Labor,” Economica, 45, 235-50.

Rosen, S. (1983), “Specialization and Human Capital,” Journal of Labor Economics, 1, 43-49.

Sachs, Jeffrey (1996), "The Tankers Are Turning - Sachs on Competitiveness," World Link, September/October 1996

Sachs, Jeffrey (1996), “On the Tigers Trail, - Sachs on Competitiveness,” World Link, November/December 1996.

Sachs, Jeffrey and Warner, Andrew (1997): "Fundamental Sources of Long-Run Growth." American Economic Review, Papers and Proceedings, 87, 184-88.

Smith, Adam (1776), An Inquiry into the Nature and Causes of the Wealth of Nations, reprint, Oxford: Clarendon Press, 1976.

Yang, Xiaokai (1994), "Endogenous vs. Exogenous Comparative Advantages and Economies of Specialization vs. Economies of Scale," Journal of Economics, 60, 29-54.

Yang, Xiaokai and Ng, Yew-Kwang (1993), Specialization and Economic Organization, a New Classical Microeconomic Framework, Amsterdam: North-Holland.

Yang, Xiaokai and Ng, Siang (1998), "Specialization and Division of Labor: A Survey," in K. Arrow, Y-K Ng and $\mathrm{X}$, Yang eds. Increasing returns and Economics Analysis, London: Macmillan. 